\title{
Goal-oriented therapy in pulmonary veno-occlusive disease: a word of caution
}

\section{To the Editors:}

The evidence for using pulmonary arterial hypertension (PAH) therapies such as prostacyclin derivatives, endothelin receptor antagonists and type- 5 phosphodiesterase inhibitors in pulmonary veno-occlusive disease (PVOD) is modest and conflicting [1, 2]. Indeed, despite several reports of clinical deterioration and life-threatening pulmonary oedema in PVOD patients receiving PAH therapies, we have recently shown in the European Respiratory Journal that cautious use of continuous intravenous epoprostenol alone or in combination with endothelin receptor antagonists may be useful as a bridge therapy to lung transplantation [2].

The term "goal-oriented therapy" describes a relatively novel therapeutic approach in the field of $\mathrm{PAH}$, which focuses on the question of when a response to therapy can be considered sufficient and when it cannot [3]. This question is of fundamental importance in guiding therapeutic decisions: that is, when to maintain a therapy, when to switch from one medication to another and when to combine several medications. As an inadequate response to first-line $\mathrm{PAH}$ medical treatments is frequently observed in PVOD patients [1], it is likely that a significant proportion of patients showing insufficient response to first-line $\mathrm{PAH}$ therapy could be candidates for sequential add-on combination therapy and that such a strategy might increase the risk of developing pulmonary oedema. This eventuality may be more likely in scleroderma patients, who are prone to present with significant pulmonary venous involvement [4]. We report a case of severe pulmonary oedema occurring in a scleroderma patient with PVOD who was offered sequential combination therapy with sildenafil in a goal-oriented strategy after inadequate response to first-line bosentan.

We report the case of a 45-yr-old female who developed rapidly progressive dyspnoea (New York Heart Association (NYHA) functional class III) with episodes of thoracic pain. A limited systemic scleroderma was diagnosed 5 yrs previously, with no history of pulmonary, renal or cardiac involvement. On admission, ECG showed complete right branch block and right axis deviation, and echocardiography estimated systolic pulmonary artery pressure $(\mathrm{Ppa})$ at $67 \mathrm{mmHg}$. Right heart catheterisation confirmed severe pre-capillary pulmonary hypertension (table 1). Pulmonary function tests and arterial blood gases

TABLE 1 Evolution of functional and haemodynamic characteristics

\begin{tabular}{|c|c|c|c|c|}
\hline NYHA FC & III & III & IV & IV \\
\hline Pra $\mathrm{mmHg}$ & 3 & 13 & 4 & - \\
\hline $\bar{P}_{\text {pa }} \mathrm{mmHg}$ & 44 & 45 & 58 & - \\
\hline TPRi & 864 & 1043 & 1462 & - \\
\hline PVRi & 765 & 904 & 1363 & - \\
\hline $\mathrm{Sv}, \mathrm{O}_{2} \%$ & 73 & 69 & 68 & - \\
\hline Acute vasodilator testing & Negative & - & - & - \\
\hline 6MWD m & 363 & 390 & 338 & 0 \\
\hline BNP $\mathrm{pg} \cdot \mathrm{mL}^{-1}$ & 46 & - & 56 & 715 \\
\hline \multirow[t]{2}{*}{ Modification of specific PAH therapy } & Start of bosentan therapy & Bosentan monotherapy & Addition of sildenafil & Stop sildenafil \\
\hline & & & & $\begin{array}{l}\text { Listed for urgent lung } \\
\text { transplantation }\end{array}$ \\
\hline
\end{tabular}

PAH: pulmonary arterial hypertension; NYHA: New York Heart Association; FC: functional class ; Pra: right atrial pressure; $\bar{P}_{\text {pa: }}$ mean pulmonary arterial pressure; Ppcw: pulmonary capillary wedge pressure; $\mathrm{Cl}$ : cardiac index; TPRi: total pulmonary resistance index; PVRi: pulmonary vascular resistance index; $\mathrm{Sv}_{1} \mathrm{O}_{2}$ : mixed venous oxygen saturation; 6MWD: 6-min walk distance; $\mathrm{DL}, \mathrm{CO}$ : diffusing capacity of the lung for carbon monoxide; $V_{\mathrm{A}}$ : alveolar volume; $\mathrm{Pa}_{\mathrm{a}} \mathrm{O}_{2}$ : arterial oxygen tension; BNP: brain natriuretic peptide. 

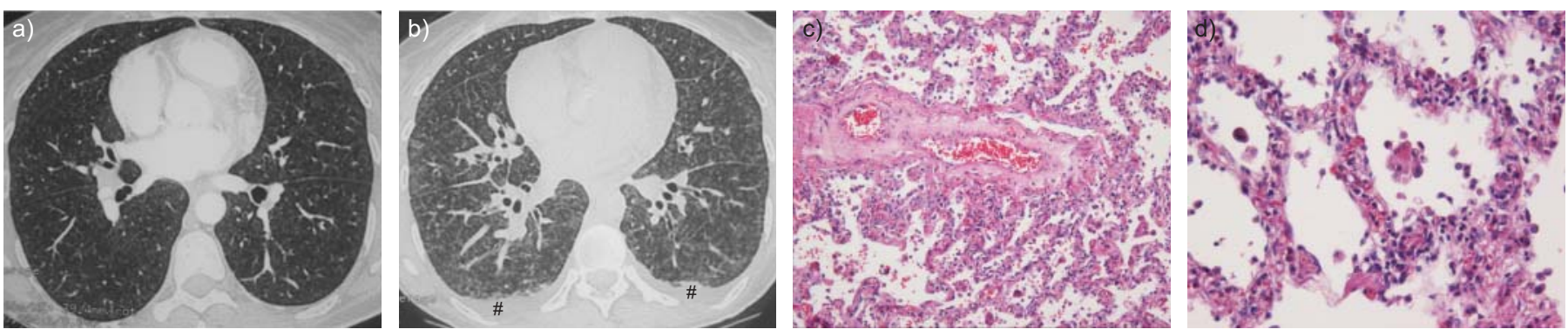

FIGURE 1. Pulmonary veno-occlusive disease (PVOD): high-resolution computed tomography (HRCT) of the chest and lung pathology. a) HRCT of the chest after 6 months of bosentan monotherapy showing predominantly mild centrilobular ground-glass opacities and septal lines. b) HRCT of the chest 2 months after addition of sildenafil to bosentan therapy showing marked pulmonary oedema with ground-glass opacities, septal lines and bilateral pleural effusion. c and d) Pathological assessment of explanted lungs demonstrating characteristic features of PVOD, including occlusive venopathy (c) and capillary proliferation (d) (haematoxylin-eosin-saffron staining).

showed low diffusing capacity of the lung for carbon monoxide $(D \mathrm{~L}, \mathrm{CO} ; 49 \%)$ and hypoxaemia at rest (arterial oxygen tension $\left.\left(\mathrm{Pa}, \mathrm{O}_{2}\right) 67 \mathrm{mmHg}\right)$. 6-min walk distance was $363 \mathrm{~m}$ (table 1). High-resolution computed tomography (HRCT) of the chest showed patchy areas of centrilobular ground-glass opacities, septal lines and mediastinal lymphadenopathy. Bronchoalveolar lavage revealed an occult alveolar haemorrhage. These findings were highly suggestive of PVOD. Cautious use of the dual endothelin receptor antagonist bosentan was proposed, together with diuretics and anticoagulants. At 3 months of bosentan therapy, the patient was clinically stable with a moderate deterioration in haemodynamics (table 1) and no clinical or radiological evidence of pulmonary oedema. After 6 months, the patient was in NYHA functional class IV with a clear deterioration of functional and haemodynamic parameters but there was still no evidence of pulmonary oedema on chest radiography and HRCT of the chest (fig. 1a) and brain natriuretic peptide (BNP) plasma levels were normal. Sildenafil, a type- 5 phosphodiesterase inhibitor, was therefore added to bosentan (table 1). 2 months after addition of sildenafil to bosentan, the patient was hospitalised in the intensive care unit with severe hypoxaemia, bilateral pleural effusions, elevated $\mathrm{BNP}\left(715 \mathrm{pg} \cdot \mathrm{mL}^{-1}\right)$ and marked radiological abnormalities suggestive of pulmonary oedema on HRCT of the chest (fig. 1b). Sildenafil was stopped, and i.v. diuretics and dobutamine were initiated, leading to a clinical improvement. The patient was listed for urgent doublelung transplantation and was transplanted within $48 \mathrm{~h}$. Pathological assessment of the explanted lungs confirmed PVOD (fig. 1c and d). The patient is still alive and well more than $1 \mathrm{yr}$ after surgery.

PVOD is a rare cause of pulmonary hypertension characterised by specific pathological changes in post-capillary venous pulmonary vessels [1]. PVOD is usually considered to represent $5-10 \%$ of patients initially diagnosed with "primary" (idiopathic) pulmonary hypertension [1]. It is believed to be even more common in patients with scleroderma-associated pulmonary hypertension [1, 4]. A better understanding of different clinical presentation and outcomes in PVOD patients $[1,5]$ has led to a recent update of the pulmonary hypertension classification [6]. It was indeed decided to place PVOD in a separate group together with pulmonary capillary haemangiomatosis. This group, called Groupe 1, is distinct from but very close to the PAH Group 1 [6]. Even if PVOD shares a broadly similar clinical presentation and haemodynamics with $\mathrm{PAH}$, low $\mathrm{Pa}, \mathrm{O}_{2}$, low $\mathrm{DL}, \mathrm{CO}$, occult alveolar haemorrhage and evidence of centrilobular ground-glass opacities, septal lines and lymph node enlargement on HRCT plead in favour of PVOD [1, 2, 5]. Recent reports have illustrated the occurrence of pulmonary oedema in PVOD patients treated with different PAH therapies (epoprostenol and prostacyclin derivatives, endothelin receptor antagonists, calcium channel-blockers) [1] It has been suggested that pulmonary oedema is due to a relative vasodilatation of the pre-capillary resistance vessels more so than the post-capillary vessels, associated with increased blood flow leading to an increase of trans-capillary hydrostatic pressure [1]. In addition, lymphatic involvement is frequently observed in PVOD and may participate in the mechanism of pulmonary oedema by a decrease in fluid resorption [7]. However, clinical stabilisation or mild improvement has been observed in cases of PVOD patients receiving $\mathrm{PAH}$ therapies [1, 2]. To our knowledge, the present case is the first report of pulmonary oedema following initiation of sildenafil in a patient receiving another specific PAH therapy, emphasising the increased risk of developing drug-induced pulmonary oedema when sequential combination therapy is proposed to PVOD patients. In this case, the relative contribution of bosentan and sildenafil therapy to pulmonary oedema may be debated, but it is likely that sequential addition of treatments in a goal-oriented strategy favoured the development of pulmonary oedema.

In conclusion, this report confirms that PVOD may be a cause of refractory pulmonary hypertension. Moreover, it shows that PAH mono- or combination therapies should be used with caution in PVOD even if first-line monotherapy was not complicated by the occurrence of pulmonary oedema. We always recommend close medical monitoring and use of highdose diuretics to reduce the risk of severe pulmonary oedema in PVOD patients. Importantly, such patients are candidates for lung transplantation which represents the best treatment option in PVOD [1, 2].

\section{Montani, X. Jaïs, P. Dorfmuller, G. Simonneau, O. Sitbon and M. Humbert}

Université Paris-Sud 11, Centre National de Référence de l'Hypertension Pulmonaire Sévère, Service de Pneumologie et Réanimation Respiratoire, Hôpital Antoine-Béclère, Assistance Publique Hôpitaux de Paris, Clamart, France. 
Correspondence: D. Montani, Service de Pneumologie et Réanimation Respiratoire, Hôpital Antoine-Béclère, 157 rue de la Porte de Trivaux, 92140 Clamart, France. E-mail: david.montani@abc.aphp.fr

Support Statement: This study has been supported, in part, by grants from Ministère de 1'Enseignement Supérieur et de la Recherche and the Université Paris-Sud 11 (both Paris, France).

Statement of Interest: Statements of interest for O. Sitbon and M. Humbert can be found at www.erj.ersjournals.com $/ \mathrm{misc} /$ statements.dtl

\section{REFERENCES}

1 Montani D, Price LC, Dorfmuller P, et al. Pulmonary veno-occlusive disease. Eur Respir J 2009; 33: 189-200.
2 Montani D., Jaïs X., Price LC., et al. Cautious use of epoprostenol therapy is a safe bridge to lung transplantation in pulmonary venoocclusive disease. Eur Respir J 2009; [Epub ahead of print DOI: 10.1183/09031936.00017809].

3 Hoeper MM, Markevych I, Spiekerkoetter E, et al. Goal-oriented treatment and combination therapy for pulmonary arterial hypertension. Eur Respir J 2005; 26: 858-863.

4 Overbeek MJ, Vonk MC, Boonstra A, et al. Pulmonary arterial hypertension in limited cutaneous systemic sclerosis: a distinctive vasculopathy. Eur Respir J 2009; 34: 371-379.

5 Rabiller A, Jais X, Hamid A, et al. Occult alveolar haemorrhage in pulmonary veno-occlusive disease. Eur Respir J 2006; 27: 108-113.

6 Simonneau G, Robbins IM, Beghetti M, et al. Updated Clinical Classification of Pulmonary Hypertension. J Am Coll Cardiol 2009; 54: Suppl. 1, S43-S54.

7 Pietra GG, Capron F, Stewart S, et al. Pathologic assessment of vasculopathies in pulmonary hypertension. J Am Coll Cardiol 2004; 43: Suppl. 12, 25S-32S.

DOI: 10.1183/09031936.00102609 